\title{
P6 acupressure increases tolerance to nauseogenic motion stimulation in women at high risk for PONV
}

\author{
[L'acupression en P6 augmente la tolérance à la stimulation nauséogène du mou- \\ vement chez des femmes à haut risque de NVPO]
}

Aidah Alkaissi RN PhD, ${ }^{*}$ Torbjörn Ledin MD PhD, $†$ Lars M. Odkvist MD PhD, $†$ Sigga Kalman MD PhD*

Purpose: In a previous study we noticed that P6 acupressure decreased postoperative nausea and vomiting (PONV) more markedly after discharge. As motion sickness susceptibility is increased by, for example, opioids we hypothesized that P6 acupressure decreased PONV by decreasing motion sickness susceptibility. We studied time to nausea by a laboratory motion challenge in a group of volunteers, during P6 and placebo acupressure.

Methods: 60 women with high and low susceptibilities for motion sickness participated in a randomized and double-blind study with an active $\mathrm{P} 6$ acupressure, placebo acupressure, and a control group ( $n=20$ in each group). The risk score for PONV was over $50 \%$. The motion challenge was by eccentric rotation in a chair, blindfolded and with chin to chest movements of the head. The challenge was stopped when women reported moderate nausea. Symptoms were recorded.

Results: Mean time to moderate nausea was longer in the P6 acupressure group compared to the control group. P6 acupressure = 352 (259-445), mean (95\% confidence interval) in seconds, control $=|5|(|2|-|8|)$ and placebo acupressure = $280(|6|-340)$; $(P=0.006)$. No difference was found between P6 and placebo acupressure or placebo acupressure and control groups. Previous severity of motion sickness did not influence time to nausea $(P=$ $0.107)$. The cumulative number of symptoms differed between the three groups $(P<0.05)$. Fewer symptoms were reported in the P6 acupressure compared to the control group $P<0.009$. Overall, P6 acupressure was only marginally more effective than placebo acupressure on the forearms.

Conclusion: In females with a history of motion sickness P6 acupressure increased tolerance to experimental nauseogenic stimuli, and reduced the total number of symptoms reported.
Objectif : Nous avions expérimenté déjà que l'acupression en P6 diminuait davantage les nausées et les vomissements postopératoires (NVPO) après l'hospitalisation. Comme la susceptibilité au mal des transports est augmentée par les opioïdes, entre autres, nous avons pensé que l'acupression en P6 diminuerait les NVPO en réduisant la susceptibilité au mal des transports. Nous avons mesuré le temps écoulé avant les premières nausées lors de d'une épreuve de mouvement chez des volontaires pendant l'application d'acupression en P6 ou d'un placebo.

Méthode : Notre essai randomisé et à double insu a réuni 60 femmes, peu ou très sujettes au mal des transports, réparties en trois groupes: avec acupression active en P6, acupression placebo, ou groupe témoin ( $n=20$ dans chaque groupe). L'évaluation des risques de NVPO était de plus de $50 \%$. L'épreuve de mouvement consistait en une rotation excentrique dans une chaise, les yeux bandés, et en des mouvements de la tête vers la poitrine. L'épreuve était arrêtée quand les femmes avaient des nausées modérées. Les symptômes étaient notés.

Résultats : Le temps moyen écoulé avant l'apparition de nausées modérées a été plus long dans le groupe avec acupression en P6 comparé au groupe témoin. Acupression en P6 = 352 (259-445), moyenne (intervalle de confiance de $95 \%$ ) en secondes, groupe témoin $=151(|2|-|8|)$ et acupression placebo $=280$ ( $161-340) ;(P=0,006)$. Aucune différence n'a été trouvée entre les groupes d'acupression en P6 et placebo ou entre les groupes placebo et témoin. La sévérité du mal des transports préalable n'a pas eu d'influence sur le temps écoulé avant les nausées $(P=0,107)$. L'ensemble des symptômes differe entre les trois groupes $(P<0,05)$. Moins de symptômes ont été rapportés chez les patientes soumises à l'acupression en $P 6$ comparées aux témoins $P<0,009$. Sur l'ensemble, l'acupression en P6 n'a été que marginalement plus efficace que le placebo appliqué sur les avant-bras.

From the Departments of Anaesthesiology and Intensive Care, ${ }^{*}$ and Oto-Rhino-Laryngology, $†$ University Hospital, Linköping, Sweden. Address correspondence to: Dr. Aidah Alkaissi, Department of Anaesthesiology and Intensive Care, University Hospital in Linköping,

SE-581 85 Linköping, Sweden. E-mail: aa1999@doctor.com; aidah.alkaissi@lio.se

Financial support was provided by the Health Research Council in the South-East of Sweden (project F 00-60/1426). Assessed May 11, 2004.

Accepted for publication October 21, 2004.

Final revision accepted February 8, 2005. 
Conclusion : Chez des femmes qui présentent des antécédents de mal des transports, l'acupression en P6 augmente la tolérance aux stimuli nauséogènes expérimentaux et réduit en nombre la fréquence des symptômes.

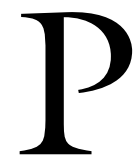
OSTOPERATIVE nausea and vomiting (PONV) can be exacerbated by movement such as transport on a trolley, change in position in bed and, after day-case surgery, transport home or activity at home. ${ }^{1}$ A history of motion sickness is also an independent predictor of PONV. ${ }^{2}$ Recent evidence suggests that P6 acupressure may decrease symptoms of motion sickness, ${ }^{3}$ and that these effects may be particularly beneficial after day case surgery. ${ }^{4,5}$ Could it be that P6 stimulation is mainly effective on movement-induced nausea?

The main signs and symptoms of motion sickness are nausea, pallor, cold sweating, and vomiting. However, many other symptoms of motion sickness are reported to varying degrees. These include apathy, general discomfort, headache, stomach awareness, increased salivation, fatigue, drowsiness, depression, warmth, dizziness, yawning, cardiac palpitations, and inability to concentrate or perform tasks. ${ }^{6,7}$

We hypothesized that women at high risk for PONV would benefit from P6 acupressure administered prior to nauseogenic stimuli. The primary outcome was the time to moderate nausea ( 3 or more on a Lickert type scale $0-6$ ) provoked by head movements in an eccentrically rotating chair. Secondary outcome measures included the number and type of symptoms reported.

\section{Methods}

The Ethics Committee at the Faculty of Health Sciences, University of Linköping, approved the investigation.

Sixty women, aged 18 to $40 \mathrm{yr}$ (mean 29, SD 6), American Society of Anesthesiologists (ASA) physical status I, with a history of motion sickness were included. The experiment was conducted in a laboratory at the Department of Otolaryngology, University Hospital of Linköping. Recruitment was from female students and staff at the University Hospital. Women with a prior history of motion sickness were included after giving informed consent. Women who had previously used acupressure bands, who had a previous experience with chair rotation, and those with a known history of visual problems, gastrointestinal, oculomotor, vestibular or central nervous system disorders were excluded. Withdrawal was possible at any stage upon request of the participant.
The study was a double-blind, randomized, placebo-controlled experiment.

Women were divided into two groups according to their own description of their susceptibility to motion sickness (low or high) and then randomized by sealed envelopes to one of three study groups. Ten women with a high susceptibility and ten women with a low susceptibility to motion sickness were included in each group. One group received P6 acupressure $(n=20)$, one group received non-acupressure stimulation $(n=20)$ and one group was used as a control group $(n=20)$.

The P6 (Nei-Guan) is located on the pericardial meridian. P6 is located three fingers breadth (approximately $5 \mathrm{~cm}$ ) proximal to the proximal flexor palmar crease, about $1 \mathrm{~cm}$ deep, between the tendons of flexor carpi radialis and palmaris longus. P6 is thought to have an effect on motion-induced nausea. ${ }^{8}$ The SeaBand ${ }^{\circledR}$ (Sea-Band UK Ltd., Leicestershire, England, UK) was used to stimulate P6. It carries a plastic pearl that applies pressure on P6. Both forearms were used.

A point on the dorsal side of both forearms, four fingers breadth proximal to the proximal flexor palmar crease was used for placebo stimulation. These points were marked in the same way as for P6 acupressure. The Sea-Band® was used for stimulation. The control group followed the same protocol as the P6 acupressure and the non-acupressure groups, but had no wristband and thus was not blinded. The Sea-Bands were covered with a dressing during the trial period. Neither the observer nor the subjects knew if P6 or placebo stimulation was given.

An eccentrically rotating chair (radius $1 \mathrm{~m}$ ) was used to stimulate nausea. The subject was positioned in the chair with a headrest designed to hold the head in a predetermined position. The headrest also served to guide downward movements of the head. The chair rotation speed was $\left(60^{\circ} / \mathrm{sec}\right)$ for all groups.

The nauseogenic motion used in this trial was a combination of head movements (chin to chest head flexion) while the subject was blindfolded and seated on the chair rotating eccentrically about a vertical axis ${ }^{9-11}$ in a darkened room with the lights turned off. The rotating chair was stopped when the women reported moderate nausea. Nausea was estimated using a sevenpoint (Lickert-type scale) in which $0=$ no nausea, $1=$ very mild, $2=$ mild, $3=$ moderate, $4=$ severe, $5=$ very severe and, 6 = worst possible nausea. After rotation was stopped the women were asked to assess their degree of nausea at two-minute intervals for $30 \mathrm{~min}$.

\section{Statistics}

Analysis of variance (ANOVA) was used to analyze differences between the three groups with respect to 
TABLE Patient demographics, and risk factors for PONV

\begin{tabular}{llll}
\hline & $\begin{array}{l}\text { P6 acupressure } \\
n=20\end{array}$ & $\begin{array}{l}\text { Pressure on a non-acupoint } \\
n=20\end{array}$ & $\begin{array}{l}\text { Control } \\
n=20\end{array}$ \\
\hline Age $(\mathrm{yr})$ & $34(5)$ & $29(5)$ & $26(5)$ \\
Body mass index $\left(\mathrm{kg} \cdot \mathrm{m}^{-2}\right)$ & $22(3)$ & $23(3)$ & $22(3)$ \\
History of previous PONV $(n)$ & 6 & 7 & 3 \\
History of motion sickness $(n)$ & 20 & 20 & 20 \\
History of sea sickness $(n)$ & 17 & 18 & 16 \\
History of flight sickness $(n)$ & 5 & 3 & 8 \\
Menstruation $(1-8$ days) $(n)$ & 8 & 7 & 4 \\
Smoker $(n)$ & 3 & 6 & 2 \\
Apfel risk score $\%$ for PONV & 58 & 54 & 58 \\
\hline
\end{tabular}

$\mathrm{PONV}=$ postoperative nausea and vomiting. Figures are given as number or mean (SD) unless otherwise stated. All patients were females.

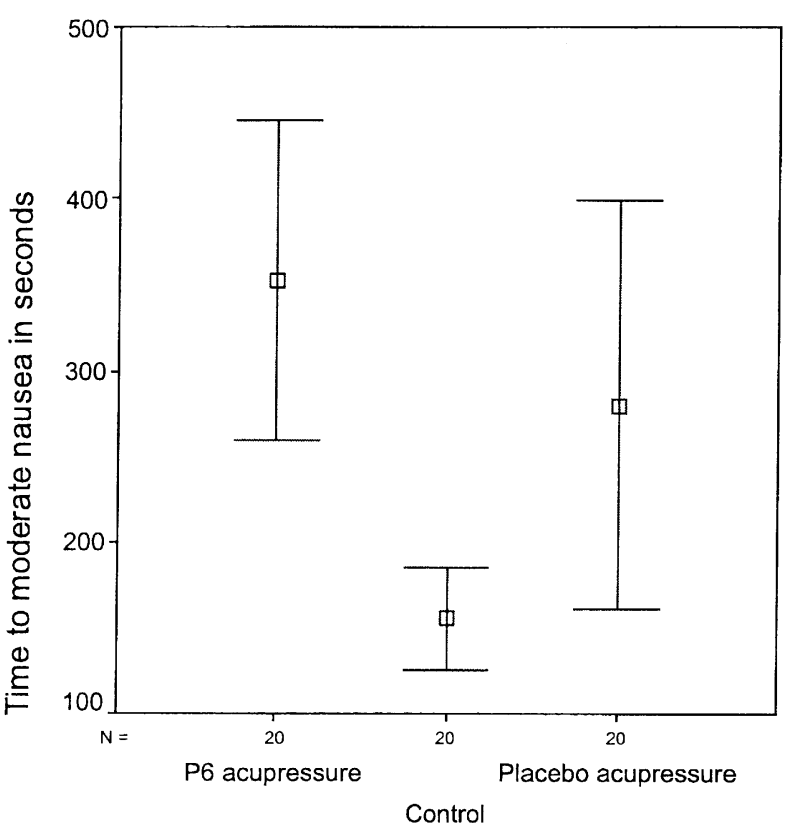

FIGURE 1 The mean time to moderate nausea (three or more on a Lickert type scale 0-6) differed between the P6 acupressure, placebo acupressure and control groups $(P=0.006)$. P6 acupressure $=352(259-445)$ mean $(95 \%$ confidence interval $)$ in seconds, control $=151(121-181)$ and placebo acupressure $=280$ $(161-340)$.

time to moderate nausea i.e., 3 on a $0-6$ Lickert type scale. If a difference was found, a post hoc analysis using Tukey's test was applied. The number of symptoms was analyzed using a Chi-square test to identify any differences in the frequency of nausea between the groups. A $P$-value $<0.05$ was considered significant. Continuous data are presented as mean (SD).

\section{Results}

All patients completed the study protocol. The three groups were similar with respect to demographic characteristics and risk factors for PONV (Table). The mean time to moderate nausea differed between the three groups $[\mathrm{F}(2.57)=5.4649, P=0.006]$; (Figure 1). Further analysis indicated that the women in the P6 acupressure group had longer time to nausea compared to the control group $(P<0.005)$ but not compared to placebo acupressure $(P=0.459)$. No difference was demonstrated between placebo acupressure and control groups $(P=0.106)$. Any difference between P6 acupressure and placebo acupressure appears to be small. Susceptibility to motion sickness had no effect on the mean time to nausea $[\mathrm{F}(1.56)=2.6789, P=0.107]$.

The number of cumulative symptoms experienced by the women differed between the three groups $(P<$ $0.05)$; (Figure 2). Relative risk reduction (RRR) for symptoms in women in the P6 acupressure was 36\% ( $P$ $<0.009)$. RRR after placebo acupressure was $24 \%$. No significant difference was demonstrated between P6 and placebo acupressure and between placebo acupressure and control groups $(P=0.080)$. The frequency of individual symptoms is presented in Figure 3 . The intensity of nausea declined time in a similar fashion in all groups.

Adverse effects included a feeling that the bands were uncomfortable and tight $(n=2)$ in the P6 acupressure group, and complaints of swelling of the hands $(n=1)$ in the placebo acupressure group.

\section{Discussion}

P6 acupressure increased time to onset of nausea and fewer symptoms were reported but no difference could be demonstrated between P6 acupressure and placebo. This seems to imply that P6 acupressure is only marginally more effective than placebo stimulation. 


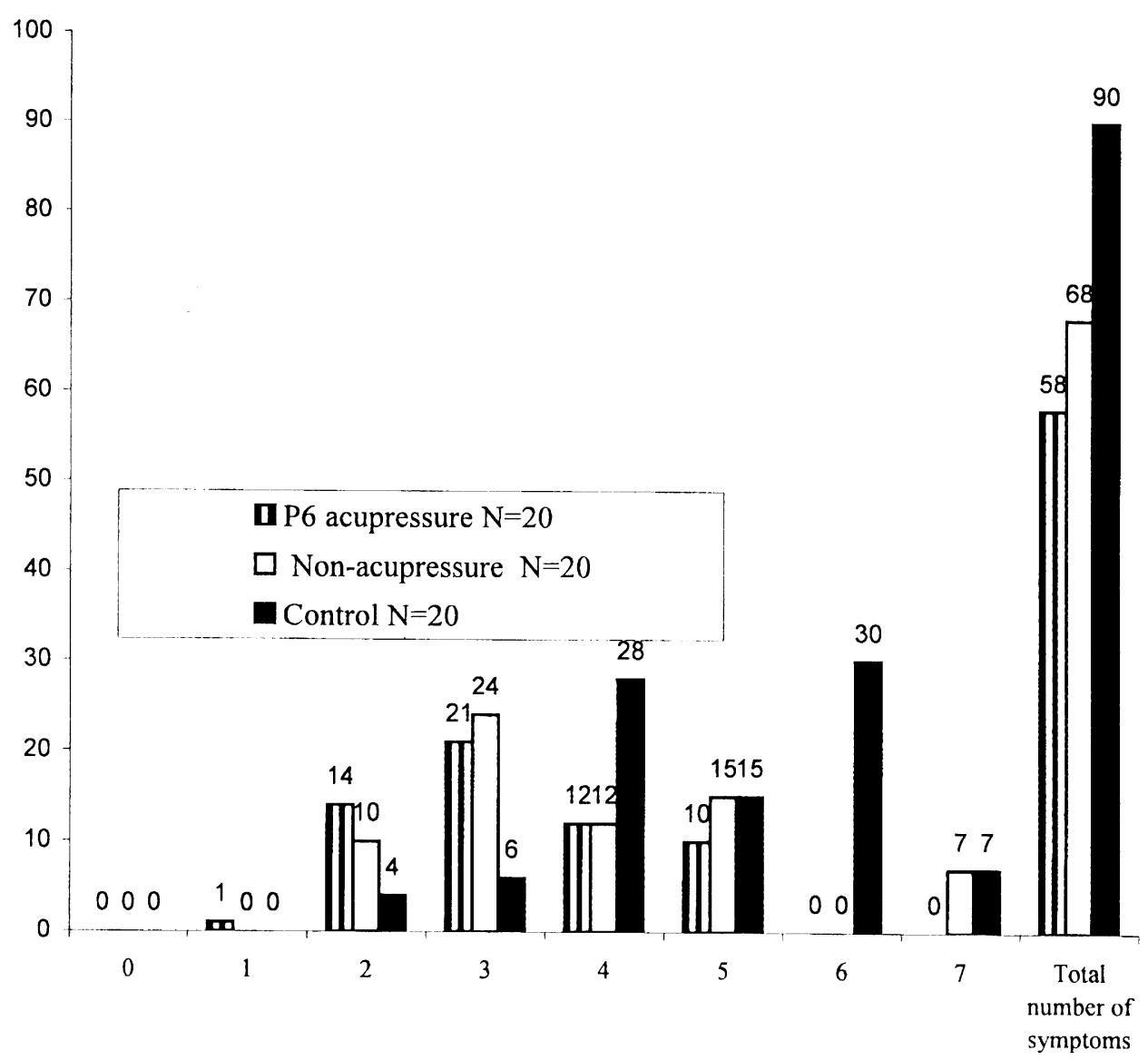

FIGURE 2 Cumulative number of symptoms experienced by subjects differed between the three groups (P6 acupressure, non-acupressure and control). Women given P6 acupressure had significantly fewer symptoms compared to the control group $(P=0.009)$.

That P6 acupressure may reduce symptoms of motion sickness ${ }^{5}$ has been reported before. Experimental studies however have produced conflicting results. ${ }^{10,12}$ The two studies which report no effect of P6 acupressure compared P6 stimulation with placebo stimulation and had no control groups. ${ }^{10,12}$ This is interesting since we could not demonstrate any difference between placebo and P6 stimulation but only between P6 and the control group. It seems that the application of placebo acupressure is also effective and, in our study, the difference between P6 and placebo stimulation was small. A power analysis estimates that 95 patients would be required in each group to show a significant difference between P6 acupressure and placebo.

The RRR of symptoms with P6 acupressure or non-acupressure stimulation in the present study was
$36 \%$ and $24 \%$. The typical response rate to placebo (saline) treatment for established PONV ranges from 14 to $20 \%{ }^{13}$ According to theories of Traditional Chinese Medicine, effective points in treatment of disease are always connected to meridians in the human body. ${ }^{14}$ The placebo point used in the experiment is not located on a particular meridian, so less symptom reduction would be expected. The mechanism whereby P6 acupressure reduces symptoms of motion sickness is still unknown. Researchers have suggested that acupuncture increases endorphine levels ${ }^{15}$ and adjustment of autonomic nerves. ${ }^{16}$

There is accumulating evidence that P6 acupressure is effective against PONV. ${ }^{3,4,17}$ We have shown that this intervention increases time to nausea after motion stimulation. Even though there is a placebo effect the only significant difference was between P6 acupressure 


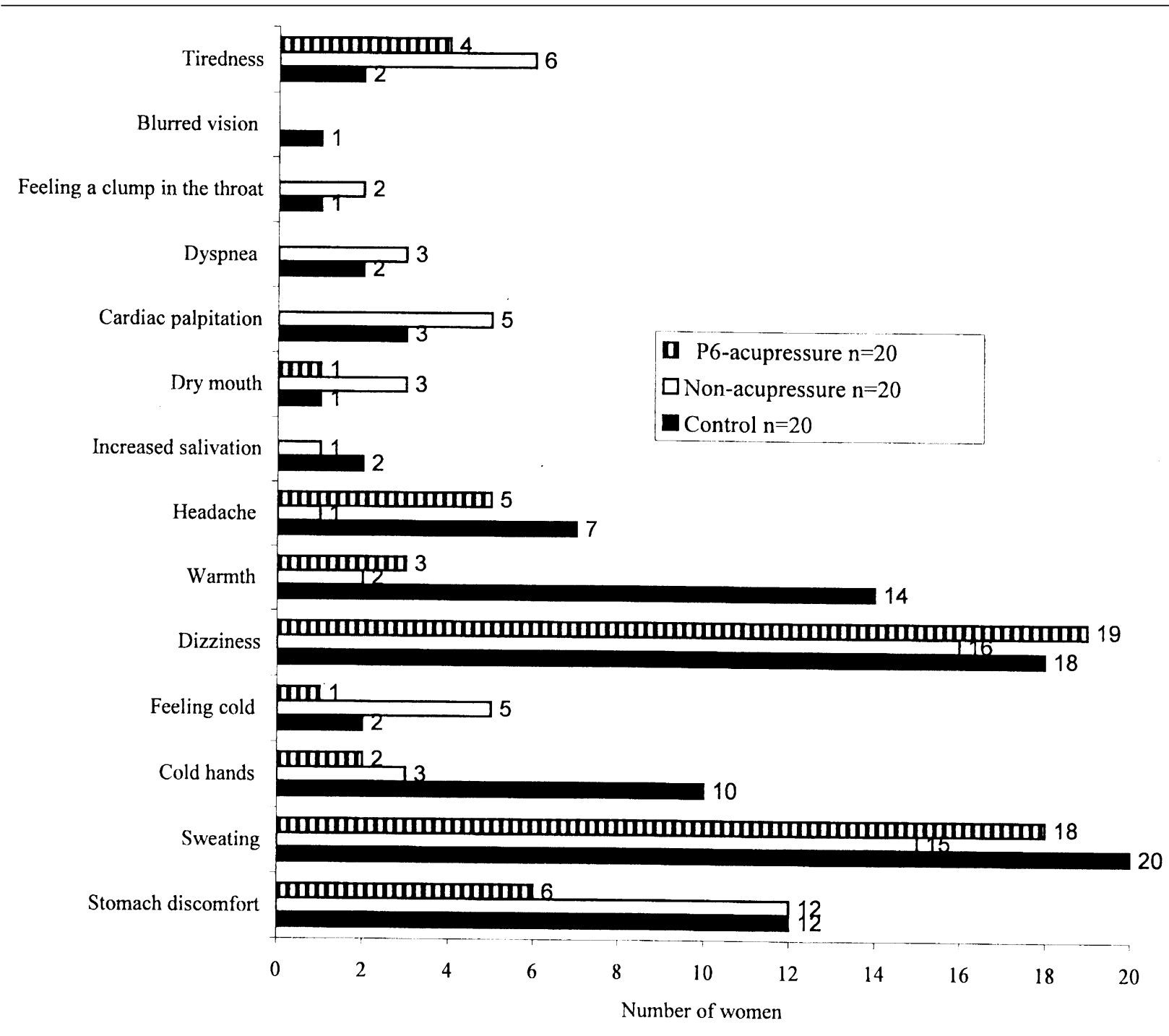

FIGURE 3 Individual symptoms reported by subjects when provoked in the controlled laboratory situation. Rotation was stopped when the subjects reported nausea as moderate.

and the control group. Perceived treatments are known to have a powerful placebo effect. ${ }^{18}$ We used

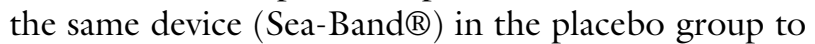
ensure a similar sensory stimulation. Stimulation of a dummy point has consistently proved less effective than stimulation of P6. ${ }^{19}$ Therefore we recommend that the P6 point should be used if an antinausea effect is sought.

In our study we used a standardized nauseogenic motion challenge. It has been well established that nodding head movements concomitant with body rotation around the vertical axis results in an intense stimulation of the vestibular receptors of the inner ear (the Coriolis effect), thereby inducing motion sickness. ${ }^{9}$ It has also been proposed that vestibulosympathetic reflexes contribute to autonomic responses of a prone individual during head-down neck flexion. ${ }^{20}$ The motion profile used in the present study is an unusual one and, as such, is a powerful stimulus for motion sickness. This motion profile has been used in earlier studies ${ }^{10}$ evaluating the effect of antiemetics such as scopdamine. 
We studied females as they generally experience motion sickness more frequently, ${ }^{2}$ with greater severity and with more gastrointestinal symptoms than males, ${ }^{21}$ though the role of gender has been questioned by others. ${ }^{22}$ We did not use a crossover design ${ }^{10}$ as repeated exposure to a particular nauseogenic stimulus leads to a gradual reduction and eventual disappearance of the symptoms of motion sickness. ${ }^{23}$ Psychological factors have a strong influence on the development of motion sickness, especially in a situation that has previously been associated with motion sickness. ${ }^{24}$ The study of populations with different susceptibilities to motioninduced nausea could lead to an incorrect conclusion. Thus, we stratified the study groups according to susceptibility to motion sickness.

The women were requested to refrain from eating or drinking two hours prior to the motion challenge. We hypothesized that a state of enhanced parasympathetic tone (e.g., elicited by food intake) would reduce the occurrence of gastric dysrrhythmia. Increased vagal tone (as a result of eating) reduces the severity motion sickness. ${ }^{25}$

In summary, P6 acupressure doubles the time to moderate nausea after an experimental nauseogenic stimulus and reduces the total number of symptoms reported. P6 acupressure is only marginally more effective than placebo acupressure on the dorsal side of the forearms. Only minor adverse effects were observed with this technique.

\section{Acknowledgements}

We thank vestibular assistant Lisbeth Noaksson and engineer Susanne Olsson for their advice and technical performance of the rotation challenge.

\section{References}

1 Kamath B, Curran J, Hawkey C, et al. Anaesthesia, movement and emesis. Br J Anaesth 1990; 64: 728-30.

2 Apfel CC, Läärä E, Koivuranta M, Creim CA, Roewer $N$. A simplified risk score for predicting postoperative nausea and vomiting. Conclusions from cross-validations between two centers. Anesthesiology 1999; 91: 693-700.

3 Bertolucci LE, DiDario B. Efficacy of a portable acustimulation device in controlling seasickness. Aviat Space Environ Med 1995; 66: 1155-8.

4 Alkaissi A, Stålnert M, Kalman S. Effect and placebo effect of acupressure (P6) on nausea and vomiting after outpatient gynaecological surgery. Acta Anaesthesiol Scand 1999; 43: 270-4.

5 Alkaissi A, Evertsson K, Johnsson VA, Ofenbartl L, Kalman S. P6 acupressure may relieve nausea and vomiting after gynecological surgery: an effectiveness study in 410 women. Can J Anesth 2002; 49: 1034-9.

6 Cowings PS, Toscano WB. Autogenic-feedback training exercise is superior to promethazine for control of motion sickness symptoms. J Clin Pharmacol 2000; 40: 1154-65.

7 Hoffer ME, Gottshall K, Kopke RD, et al. Vestibular testing abnormalities in individuals with motion sickness. Otol Neurotol 2003; 24: 633-6.

8 A Barefoot Doctor's Manual (The American Translation of The Official Chines Paramedical Manual). Philadelphia: Running Press; 1990.

9 Jobnson WH, Stubbs RA, Kelk GF, Franks WR. Stimulus required to produce motion sickness. 1. Preliminary report dealing with importance of head movements. J Aviat Med 1951; 22: 3 65-74.

10 Bruce DG, Golding JF, Hockenbull N, Pethybridge RJ. Acupressure and motion sickness. Aviat Space Environ Med 1990; 61: 361-5.

11 Ödkvist L. Clinical and instrumental investigational otolith function. Adv Otorhinolaryngol 2001; 58: 68-76.

12 Warwick-Evans LA, Masters IJ, Redstone SB. A doubleblind placebo controlled evaluation of acupressure in the treatment of motion sickness. Aviat Space Environ Med 1991; 62: 776-8.

13 Tramèr MR, Moore RA, Reynolds DJ, McQuay HJ. A quantitative systematic review of ondansetron in treatment of established postoperative nausea and vomiting. BMJ 1997; 314: 1088-92.

14 Beijing College of Traditional Chinese Medicine, et al. Essentials of Chinese Acupuncture. Beijing: Beijing Foreign Language Press; 1980.

15 Clement-Jones V, McLoughlin L, Tomlin S, Besser GM, Rees LH, Wen HL. Increased $B$-endorphin but not metenkephalin levels in human cerebrospinal fluid after acupuncture for recurrent pain. Lancet 1980; 2: 946-8.

16 Yang LG, Jawan B, Chen CN, Ho RT, Chang KA. Lee $J H$. Comparison of P6 acupoint injection with $50 \%$ glucose in water and intravenous droperidol for prevention of vomiting after gynecological laparoscopy. Acta Anaesthesiol Scand 1993; 37: 192-4.

17 NIH Consensus Conference. Acupuncture: NIH consensus development panel on acupuncture. JAMA 1998; 280: 1518-24.

18 Roberts AH, Kewman DG, Mercier L, Hovell M. The power of nonspecific effects in healing: implications for psychosocial and biological treatments. Clin Psych Review 1993; 13: 375-91.

19 Linde K, Vickers A, Hondras $M$, et al. Systematic reviews of complementary therapies - an annotated bibliography. Part 1: acupuncture. BMC 
Complementary and Alternative Mecicine 2001; 1: 3 .

20 Ray CA, Hume KM. Neck afferents and muscle sympathetic activity in humans: implications for the vestibulosympathetic reflex. J Appl Physiol 1998; 84: 450-3.

21 Jokerst MD, Gatto M, Fazio R, Gianaros PJ, Stern RM, Koch KL. Effects of gender of subjects and experimenter on susceptibility to motion sickness. Aviat Space Environ Med 1999; 70: 962-5.

22 Cheung B, Hofer K. Lack of gender difference in motion sickness induced by vestibular Coriolis crosscoupling. J Vestib Res 2002-2003; 12: 191-200.

23 Parker DE, Paker KL. Adaptation to the simulated stimulus rearrangement of weightlessness In: Cramption GH (Ed.). Motion and Space Sickness. Boca Raton, FL: CRC Press; 1990: 247-61.

24 Wood CD. Antimotion sickness and antiemetic drugs. Drugs 1979; 17: 471-9.

25 Uijtdehaage SH, Stern RM, Koch KL. Effects of eating on vection-induced motion sickness, cardiac vagal tone, and gastric myoelectric activity. Psychophysiology 1992; 29: 193-201. 